\title{
25 Research Square \\ Identification of occult hepatitis B virus infection in blood donors with non-discriminated reactive in southwest China
}

\section{Qiaolin Zhang}

Chongqing Blood Center

Dan Yin ( $\nabla$ dianayin530@hotmail.com)

The First People's Hospital of Chongqing Liangjiang New Area

\section{Research Article}

Keywords: Blood screening, Nucleic acid testing (NAT), Occult hepatitis B virus infection (OBI), Blood safety

Posted Date: January 27th, 2022

DOl: https://doi.org/10.21203/rs.3.rs-1213798/v1

License: (c) (i) This work is licensed under a Creative Commons Attribution 4.0 International License.

Read Full License 


\section{Abstract \\ Background}

Since 2011, Chongqing Blood Center began routine screening of viral nucleic acid using a multiplex assay for simultaneous detection of HBV DNA, HCV RNA and HIV-1 RNA in blood donations. However, this multiplex nucleic acid testing (NAT) screening system introduced an intractable problem of nondiscriminated reactive (NDR) donations, which were serologically nonreactive and reactive in multiplex NAT screening, but nonreactive in the following virus-specific discriminatory NAT assays. Some donations were considered to arise from the presence of low-level HBV DNA due to occult hepatitis B infection $(\mathrm{OBI})$. We identified $\mathrm{OBI}$ among NDR donations in Chongqing area. In addition, rationality of the current blood screening strategy was evaluated.

\section{Methods}

From August 2017 to July 2018, 190 NDR blood donations were collected from 140577 volunteer blood donors at Chongqing Blood Center. Repeated discriminatory HBV (dHBV) testing, minipools-NAT (MPsNAT), quantitative viral load determination and complementary serological testing were used to confirm $\mathrm{OBI}$.

\section{Results}

Of 190 NDR donations, sixty-three (33.2\%) were identified as OBI, sixty-one (32.1\%) were repeatedly reactive in discriminatory HBV assay. Two (1.1\%) were positive for HBV DNA in MPX assay on Roche Cobas s201 system. Of these sixty-three OBI donations, only thirteen (20.6\%) were positive in Cobas AmpliPrep/TaqMan HBV DNA quantitative assay, which were all less than $20 \mathrm{IU} / \mathrm{ml}$. Anti-HBc and antiHBs were detected in $85.3 \%$ and $58.4 \%$ of NDR donors, respectively. Anti-HBc and anti-HBs were detected in $96.8 \%$ and $47.6 \%$ of confirmed OBI donors in NDR group, respectively. Anti-HBc and anti-HBs were detected in $79.5 \%$ and $63.8 \%$ of unclassified donors in NDR group, respectively. There was no statistical difference in positive rate of anti-HBc between NDR donations and dHBV-initially-reactive donations $(85.3 \%$ vs $90.0 \%)$. The male to female ratio was 2.2 of OBI donors in NDR group. The proportion of repeat-time OBI donors in NDR group was higher than that in dHBV-initially-reactive group $(63.5 \% \mathrm{vs}$ $50.0 \%$ ). The median age of OBI donors was 45 years in NDR group.

\section{Conclusion}

A complicated $\mathrm{OBI}$ confirmatory procedure with labour-intensive and sophisticated equipment was implemented successfully. $\mathrm{OBI}$ with extremely low virus concentration is the main reason for discriminatory NAT nonreactive among blood donors in Chongqing area. The current blood screening 
strategy is a reasonable measure to reduce the risk of transfusion, which is able to maximize blood safety.

\section{Background}

Chronic hepatitis B virus (HBV) infection is a common cause of cirrhosis and hepatocellular carcinoma globally. Although hepatitis $B$ vaccine has been widely applied, there are still 257 million chronic hepatitis B patients (defined as hepatitis B surface antigen [HBsAg] positive) worldwide [1]. Other than chronic HBV infection, occult hepatitis $B$ virus infection $(O B I)$ is another clinical presentation of $\mathrm{HBV}$ infection, it is defined as HBsAg negative yet hepatitis B virus DNA positive in serum and/or liver, meanwhile HBV DNA level is usually less than $200 \mathrm{IU} / \mathrm{ml}$ (about 1,000 copies/ml) [2]. OBI is most frequently observed in patients with hepatitis $\mathrm{B}$ core antibody (anti-HBc) reactive (with or without hepatitis B surface antibody (anti-HBs))[3]. OBI has been reported as an additional risk factor for progression of nonalcoholic fatty liver disease, alcoholic liver cirrhosis, and HBV infection to hepatocellular carcinoma [4]. Through a retrospective study, some patients died of transfusion-transmissible HBV (TT-HBV) fulminant hepatitis caused by transfusion due to OBI-derived blood products [5]. Even though infection rate of such donations seems to be low, the prevalence of $\mathrm{OBI}$ in blood donors should be well evaluated, especially in HBV high-endemic areas.

Although HBsAg screening strategy has been carried out in all blood donations, blood centers in China have voluntarily implemented nucleic acid testing (NAT) to prevent TT-HBV infection since 2010. In 2015, NAT was included in the mandatory blood screening program. Chongqing is one of the four municipalities directly under the central government in China, and Chongqing Blood Center is the only blood center in Chongqing area. Since 2011, Chongqing Blood Center began routine screening of $\mathrm{HBV} / \mathrm{HCV} / \mathrm{HIV}-1$ nucleic acids in blood donations using the Procleix Ultrio assay and the Procleix Ultrio Plus assay (in place since 2016). This multiplex NAT assay proves the presence of viral genomes in the donation by detecting a single signal that does not distinguish between these three viruses. Then virusspecific discriminatory assays are used to identify the origin of the initial signal. However, this NAT screening system introduced an intractable problem of non-discriminated reactive (NDR) donations, which were serologically nonreactive and reactive in multiplex NAT screening, but nonreactive in the following discriminatory NAT assays, and which may be mainly observed in OBI donors $[6,7]$. Because the viral load of $\mathrm{OBI}$ is usually too low to be quantified or be sequenced [8]. It is reported that multiple repeated tests from the NDR donations' plasma bag may increase the chance of detecting viral nucleic acids present at levels around the assay's limit of detection (LOD) according to the Poisson distribution by alternative NATs [9]. Furthermore, repeated tests and different methods could increase the detection rate of $\mathrm{OBI}$.

Since the implementation of the hepatitis B vaccine program in China, the seroprevalence of HBV in blood donors has declined $[10,11]$. OBI donors, who with mutations that may resulted in the absence of HBsAg production [7]. Moreover, the manufacturer of Ultrio Plus stated that the multiplex NAT assay was marginally more sensitive than the discriminatory assay for detecting HBV DNA [12], which is one of the 
causes of NDR results. The characteristic of OBI with low viral load is consistent with the occurrence of NDR results. This study set out with the aim of understanding the OBI status of discriminatory-NAT nonreactive donations in Chongqing, a municipality in southwest China. Furthermore, rationality of the current blood screening strategy was evaluated.

\section{Methods}

\section{Subjects and samples}

During the period from August 2017 to July 2018, a total of 140577 blood donations were collected from Chongqing Blood Center. Among them, 67622 (48.1\%) blood donations were from first-time donors, and the rest of 72955 (51.9\%) blood donations were from repeat-time donors. In this study, we defined a firsttime donor to be someone with no history of blood donation at Chongqing Blood Center, and a repeattime donor was defined as a person who has donated blood at least twice at Chongqing Blood Center. The blood donations with HBsAg, anti-HCV, HIV Ag \& anti-HIV ELISA nonreactive and initially reactive in Ultrio Plus HBV/HCV/HIV-1 multiplex NAT assay, among which were nonreactive in the following virusspecific discriminatory assays defined as non-discriminated reactive (NDR). We collected 190 NDR donations in the experimental group and $100 \mathrm{dHBV}$-initially-reactive donations in the control group.

\section{Routine serological and nucleic acid testing}

All donations in this study were tested for HBsAg, anti-HCV, HIV Ag \& anti-HIV with enzyme-linked immunosorbent assay (ELISA) using two reagents from different manufacturers and multiplex NAT assay for HBV DNA, HCV RNA and HIV-1 RNA based on transcription-mediated amplification (TMA) was used (Procleix Ultrio Plus on Tigris platform; Grifols, Spain) for individual-donation-nucleic acid testing (ID-NAT), multiplex NAT-initially-reactive donations were discriminated with three virus-specific discriminatory NAT assays. Regardless of the discriminatory results, as long as multiplex NAT was initial reactivity, the related blood products would be eliminated.

\section{Repeated discriminatory HBV testing}

190 NDR donations were retested five times with Ultrio Plus dHBV assay. Any reactive result was identified to be positive for HBV DNA.

\section{Minipools nucleic acid testing (MPs-NAT)}

PCR Cobas multiscreen (COBAS s201, Branchburg, USA) technology in pools of six samples was used to confirm the status of donations, which were still nonreactive after five repetitions with dHBV assay. If a positive result is obtained, a resolution test will be performed to identify the specific positive one from the six donations according to the manufacturer's instruction. Donation that was reactive in both MPs-NAT and resolution test was considered to be positive for HBV DNA.

\section{Quantitative viral load determination}


HBV DNA-positive donations were tested by real-time fluorescent quantitative polymerase chain reaction (qPCR) (Cobas AmpliPrep/TaqMan HBV Test, Roche Diagnostics, Branchburg, USA). The $95 \%$ LOD of this assay is $20 \mathrm{IU} / \mathrm{ml}$.

\section{Complementary serological testing}

All donations in this study were subjected to detected anti-HBc and anti-HBs with ELISA (Wantai Diagnostics, Beijing, China) according to the manufacturer's procedures.

\section{Definition of occult HBV infections}

In this study, OBI was defined as HBV DNA positive, anti-HBc positive and/or anti-HBs positive but HBsAg negative [13].

\section{Statistical analysis}

The data in the research were analyzed using SPSS statistic version 22.0. Chi-square test was applied to determine the association between nominal data, A p-value less than 0.05 was used as the cutoff level of statistical significance.

\section{Results}

\section{Routine screening of blood donations}

During the period from August 2017 to July 2018, a total of 140577 volunteer blood donations were collected from Chongqing Blood Center. The 140577 blood donors were 51.8\% (72765) males and 48.2\% (67812) females, respectively. 190 NDR donors were distributed in $60.5 \%$ (115) males and $39.5 \%$ (75) females. There was a statistical difference in gender distribution between blood donor population and NDR donors $(\chi 2=10.6, p<0.05)$. Figure 1 shows the blood screening tests and the OBI confirmatory algorithm.

$<$ Fig. 1 >

\section{Repeated discriminatory HBV testing}

Of 190 NDR donations, sixty-one (32.1\%) were positive for HBV DNA at least once in five repeated dHBV tests. In addition, more than half (55.7\%) of these donations were reactive for dHBV only once out of five repetitions. Out of the five repeated tests, up to three more times were reactive (Table 1). The rest of 129 $(67.9 \%)$ donations were identified as negative for repeated dHBV testing. The positive rate of HBV DNA increased with the number of repetitions (Table 2).

$<$ Table 1>

$<$ Table 2> 


\section{Minipools nucleic acid testing (MPs-NAT)}

Two donations that were negative for repeated dHBV testing were positive for HBV DNA on Roche Cobas s201 system in MPs of six samples, which were identified as HBV DNA-positive. The cycle threshold (Ct) values were all less than 38 , and the minimum Ct value was 47.2 (Table 3 ).

$<$ Table 3>

\section{Quantitative viral load determination}

Of sixty-three HBV DNA-positive donations, only thirteen (20.6\%) were positive in Cobas AmpliPrep/TaqMan HBV DNA quantitative assay based on real-time fluorescent qPCR. However, the viral loads of these quantitatively-positive donations were all less than $201 \mathrm{~J} / \mathrm{ml}$, which were lower than the $95 \%$ LOD of this assay.

\section{Complementary serological testing}

Table 4 shows the distributions of HBV serological markers. The positive rate of serological markers was $100 \%(63 / 63)$ of sixty-three HBV DNA-positive donations, all of which were confirmed as serologically positive OBI donors. $96.8 \%(61 / 63)$ were anti-HBc positive and $47.6 \%(30 / 63)$ were anti-HBs positive, two only carried anti-HBs. The positive rate of serological markers was $90.6 \%(115 / 127)$ in the rest of 127 unclassified donations, 79.5\% (101/127) were anti-HBc positive and 63.8\% (81/127) were anti-HBs positive, fourteen only carried anti-HBs, and twelve had no detectable serological markers. The distribution of anti-HBc between HBV DNA-positive donations and unclassified donations had a statistical significant difference $(96.8 \%$ vs $79.5 \%, \chi 2=10.0, p<0.05)$. Likewise, similar result was obtained for anti-HBs positive rate $(47.6 \%$ vs $63.8 \%, \chi 2=4.5, p<0.05)$ between the two strains. Of 190 NDR donations, $35.3 \%(67 / 190)$ only anti-HBc positive, 50.0\% (95/190) carried both anti-HBc and anti-HBs, $8.4 \%(16 / 190)$ had only anti-HBs, and 6.3\% (12/190) showed no serological markers. Of $100 \mathrm{dHBV}$ initially-reactive donations, $57.0 \%(57 / 100)$ only anti-HBc positive, 33.0\% (33/100) carried both anti-HBc and anti-HBs, $2.0 \%(2 / 100)$ had only anti-HBs, and $8.0 \%$ (8/100) showed no serological markers. Eight donations had no detectable serological markers, which could not be confirmed as serologically negative $\mathrm{OBI}$ nor window period (WP) of HBV infection because they were not followed up. There was no statistical difference in anti-HBc-positive rate between NRD donations and dHBV-initially-reactive donations (85.3\% $[162 / 190]$ vs $90.0 \%[90 / 100], \chi 2=1.3, p>0.05)$.

$<$ Table 4>

\section{Serological distributions and population characteristics of all confirmed OBI donors}

Table 5 demonstrates that among all confirmed OBI donors in two groups, 97.4 (151/155) were anti-HBc positive, $41.9 \%$ (65/155) were anti-HBs positive. 39.4\% (61/155) donors carried anti-HBc and anti-HBs, $58.1 \%(90 / 155)$ had only anti-HBc and $2.6 \%(4 / 155)$ had only anti-HBs. There was no significant difference in serological distribution between NRD donations and dHBV-initially-reactive donations $(\chi 2$ 
$=1.4, p>0.05)$. The male to female ratio was about 2:1(103/52). There was no statistical difference in gender distribution between the two groups (2.2 [43/20] vs 1.9 [60/32], $\chi 2=0.16, p>0.05)$. The first-time donors were $44.5 \%(69 / 155)$, and the repeat-time donors were $55.5 \%(86 / 155)$. The proportion of repeattime donors in NDR group was higher than that in dHBV-initially-reactive group (63.5 \% vs $50.0 \%)$. The median age of OBI donors in NDR group was 45 years, which was similar to that was 46 years in dHBVinitially-reactive group.

$<$ Table 5>

\section{Discussion}

Occult hepatitis $B$ virus infection $(\mathrm{OBI})$ has been identified as one of the potential risk factors that threaten blood transfusion safety $[14,15]$. OBI is related to these factors such as HBV gene mutation, virus replication and low expression levels, and host's immunity status [14-16]. OBI shows undetectable HBsAg, but a sustained low or fluctuating level of HBV DNA in serum or liver. This study was based on the previous research of Chongqing Blood Center. Firstly, Ultrio Plus multiplex ID-NAT assay for simultaneous detection of HBV DNA, HCV RNA, and HIV-1 RNA was adopted, following discriminatory assays of these three viruses were carried out if the initial result was reactive. We have noted that only about a third were reactive in discriminatory assays among NDR donations. About two-thirds donations were nonreactive in discriminatory assays were defined as NDRs, which was similar to the result (68\%) previously reported by a national research in China [17].

Due to the Poisson distribution of virus particles in the sample [18], the randomness of sampling leads to non-repetitive reactivity in NAT, and the lower the virus load in the sample, the lower the probability of capturing virus particles. Five duplicate tests with Ultrio Plus dHBV assay were implemented to improve chance of sampling virus particles to confirm low-level HBV DNA such as OBI. Sixty-one NDR donations were identified to be HBV DNA-positive in repeated dHBV tests, all were confirmed as seropositive-OBI donors. Moreover, it presented the characteristic of non-repetitive reactivity, which might be related to extremely low and fluctuating levels of viral nucleic acids and was mainly observed in OBI donors [7]. Only $55.7 \%$ of HBV DNA-positive donations showed once reactivity in five repeated tests, which was also related to extremely low viral load of $\mathrm{OBI}[7,19]$. The HBV DNA-positive rate increased with the increase of repetitions, indicating that if the number of repetitions increased again, more HBV DNA-positive donations would be detected. Although increasing the number of repeated tests can improve the detection probability of samples with low viral load, the time and cost also increase, which is not feasible for general blood screening laboratory.

Different methodologies can complement each other to improve the chance of detecting HBV DNA. Ultrio Plus is an ID-NAT format assay based on transcription-mediated amplification (TMA). However, MPX is a NAT assay in MPs of six samples format based on real-time fluorescent PCR. Two donations that were negative in repeated dHBV testing were positive for HBV DNA on Cobas s201 NAT platform, all Ct values were lower than 38 and the minimum value was 47.2, further illustrating that the extremely low viral load 
of $\mathrm{OBI}$ in DNR donations. However, the reconfirmation of $\mathrm{OBI}$ in repeated-dHBV-negative donations and a higher proportion of anti-HBc positive involved in NDRs, indicating that there was a possibility of the presence of $\mathrm{OBI}$ with low-level HBV DNA in unclassified donations. Therefore, the actual proportion of OBI should be greater than $33.2 \%(63 / 190)$ confirmed this time.

Only $20.6 \%$ of HBV DNA-positive donations were detected of HBV DNA in virus load quantification, and all virus loads were less than $20 \mathrm{IU} / \mathrm{ml}$, which could not be accurately quantified. This might be due to the different sensitivity of the reagents. Ultrio Plus assay has a 95\% LOD of $3.4 \mathrm{IU} / \mathrm{ml}$ for HBV DNA, while Cobas Ampliprep/Taqman quantitative assay has a $95 \%$ LOD of $20 \mathrm{IU} / \mathrm{ml}$ for HBV DNA. The reason for the rest of 50 donations were not detected quantitatively might be that the virus loads were below the $95 \%$ LOD of the quantitative assay, or it might be that the virus loads were just around the $95 \%$ LOD. We have performed HBV DNA quantitative determination on $63 \mathrm{OBI}$ donations which initially reactive in dHBV assay, obtained a median of $108.6 \mathrm{IU} / \mathrm{ml}$, which is significantly higher than this study. This further suggests that $\mathrm{OBI}$ in NDR donors has a very low viral load.

HBV serological markers help us to identify HBV occult carriers in NDRs, especially anti-HBc and anti-HBs. In this study, the percent of anti-HBc positive in HBV DNA-positive donations (96.8\%) was significantly higher than that in unclassified donations (79.5\%). In contrary, the percent of anti-HBs positive in HBV DNA-positive donations (47.6\%) was significantly lower than that in unclassified donations $(63.8 \%)$. As is well-known, anti-HBc is considered as a vital marker related to HBV infection or exposure and anti-HBs is regarded as a kind of protective antibody, illustrating that a portion of repeated dHBV-nagative donations were false reactivity in multiplex NAT testing. Twelve donations without serological markers were also more likely to be false reactivity in multiplex NAT assay. Fourteen donations only carried anti-HBs might be false reactivity in multiplex NAT assay or they might be $\mathrm{OBI}$ with extremely low virus concentrations. The HBV DNA-positive donations were divided into two groups: anti-HBc positive and anti-HBc negative. The anti-HBc-positive rate in experimental group (96.8\%) and control group $(90.0 \%)$ was significantly higher than the anti-HBc-negative rate (3.2\% and $10.0 \%)$, indicating that there was a close relationship between HBV DNA and anti-HBc. There was no statistically significant difference in anti-HBc-positive rate between experimental group and control group, indicating that most NDR donors have been exposed to HBV, which might be potential OBI. Moreover, this is in accord with previous studies reporting that $68-91 \%$ anti-HBc positive rate of Chinese NDR donors [17, 20,21]. Based on the above results, we could draw the following conclusions: (1) anti-HBc-positive donors had a significantly higher risk of transmitting HBV through blood transfusion than anti-HBc-negative donors. However, China is a high-endemic area of HBV, the prevalence of anti-HBc in population is about $16-90 \%[22,23]$. Thus, the introduction of universal anti$\mathrm{HBc}$ to donor screening would have inevitably strain the blood supply because of the high reactivity rate. (2) There was no statistical difference in the probability of previous HBV infection or exposure between experimental group and control group. Therefore, from the perspective of blood transfusion safety, the NDR donors posed a potential risk of transmitting HBV.

There were more male $(68.3 \%$ and $65.2 \%)$ than female $(31.7 \%$ and $34.8 \%)$ donors in experimental group and control group, respectively, with nearly identical proportions in two groups. This result is consistent 
with that reported by Ramachandran et al in the United States [24]. The proportion of repeat-time donors in experimental group was higher than that in control group, indicating that the OBIs in experimental group with more lower viral loads than that in control group. These OBI donors are likely to be missed by multiplex NAT assay, which is determined by the Poisson distribution [25]. The median age of OBI was 45 years in NDR group, which was similar to previous study reporting by Deng et al in Dalian, China [26]. The Chinese government has implemented infant vaccination from 1992, and resulted in a significant reduction of carrier rate in children from 10 to $<1 \%$ over the two decades, which definitely improve the blood safety [27]. .

The non-repetitive reactivity of such low viral load donations poses serious challenges for blood screening and transfusion safety. As a result, some regions have formulated more stringent blood screening strategies based on the local HBV prevalence. For example, multiplex NAT initially-reactivedonation needs to carry out repeated testing in South Africa [28]. If the repeated result is nonreactive, then perform anti-HBc detection; if the repeated result is reactive, then carry out discriminatory tests, following plasma sample is subjected to multiplex NAT and discriminatory tests to confirm infection status of donation. However, the blood production will be eliminated regardless of the result of repeated multiplex NAT. In Japan, quantitative detection of anti-HBs and anti-HBc are adopted into blood screening, and donations with high-titer anti-HBs and low-titer anti-HBc are released. On the contrary, donations with lowtiter anti- HBs and high-titer anti-HBc are sifted out [29].

It is worth noting that the HIV WP detection rate was 1.5 per 100,000 and there was no HCV WP donor since the implementation of NAT in Chongqing Blood Center. Therefore, in-depth research related to HCV and HIV has not been carried out. However, this study included some limitations. A total of 140577 blood donations were collected, and 525 (0.37\%) donations were HBsAg, anti-HCV and HIV Ag \& anti-HIV ELISA nonreactive and Ultrio Plus multiplex NAT initially reactive, among which 206 donations $(0.15 \%)$ were both reactive in multiplex NAT and dHBV assay. Only one donation was reactive in multiplex NAT and dHIV assay, and the other $318(0.23 \%)$ were nonreactive in discriminatory assays. The NDR rate obtained in Chongqing blood donors was similar to that reported in Shenzhen $(0.21 \%)$, South China, but it was still higher than in Dalian, Northeast, China $(0.10 \%)$ and New Zealand $(0.09 \%)$ when using the same NAT assay $[19,20,26]$. The differences observed between studies might relate to differences in the regional prevalence of HBV infection. For some objective reasons, we only collected 190 DNR donations. According to the ratio, we infer that the proportion of OBI in NDRs is approximately 7.5 per 10000 donations. Since $79.5 \%$ of the NDR donors with unconfirmed HBV DNA were anti-HBc positive and some of these might have had viral loads below the 95\% LOD of Ultrio Plus multiplex assay and confirmatory reagents. Thus, the data would be underestimated.

\section{Conclusion}

In summary, we used a variety of complementary experiments and methods to confirm OBI in the donations with nonreactive results in virus-specific discriminatory assays. However, the confirmation process is complicated, time-consuming, labour-intensive and required sophisticated equipment, which is 
not feasible for general screening laboratory. In Chongqing area, $\mathrm{OBI}$ with extremely low virus concentration is the main reason for the occurrence of NDR donations. Therefore, the current screening strategy is a reasonable measure to reduce the risk of blood transfusion and ensure maximal blood safety. At the same time, we should also be aware that even if more sensitive NAT assays are implemented, it is still challenging to distinguish true positive from low-level viral loads blood donors.

\section{Abbreviations}

HBV

Hepatitis B virus

HIV-1

Human immunodeficiency virus-1

HCV

Hepatitis $C$ virus

DNA

Deoxyribonucleic acid

RNA

Ribonucleic acid

$\mathrm{OBI}$

Occult HBV infection

HBsAg

Hepatitis $B$ surface antigen

Anti-HBc

Antibody to hepatitis $B$ virus core antigen

Anti-HBs

Antibody to hepatitis B surface antigen

Anti-HCV

Antibody to Hepatitis $\mathrm{C}$ virus

HIV Ag

Human immunodeficiency virus antigen

Anti-HIV

Antibody to Human immunodeficiency virus

TT-HBV

Transfusion-transmissible HBV

NAT

Nucleic acid testing

dHBV

discriminatory testing for HBV DNA

NDR

non-discriminated reactive 
ELISA

Enzyme-linked immunosorbent assay

TMA

Transcription-mediated amplification

PCR

Polymerase chain reaction

LOD

Limit of detection

WP

Window period

ID

Individual donation

$\mathrm{MP}(\mathrm{s})$

Minipool(s)

Ct

Cycle threshold

\section{Declarations}

\section{Acknowledgements}

Thanks to the staff of Chongqing Blood Center and blood donors who participated in this study. Funding

This work was supported by the grants from Chongqing Municipal Health Commission Scientific Research Project (No. 2017MSXM130 and No. 2022WSJK047).

\section{Availability of data and materials}

The data presented in this study were collected from the data bank of blood donors available at Chongqing Blood Center. All data generated or analyzed during this study are included in this published article (and its supplementary information files).

\section{Authors' contributions}

Dan Yin designed the study and analyzed the data, Qiaolin Zhang and Dan Yin performed the experiments, Qiaolin Zhang and Dan Yin wrote the manuscript. All authors have read and approved the final manuscript.

\section{Consent for publication}

Not applicable.

\section{Competing interests}


The authors declare that they have no competing interests.

\section{Ethics approval and consent to participate}

All donors signed an informed consent prior to donating blood that includes the use of data for research and publication with delinking of personal identifier. This study was approved by the Medical Ethics Committee of Chongqing Blood Center. All experiments and methods were carried out in accordance with relevant guidelines and regulations.

\section{References}

1. Goldstein ST, Alter MJ, Williams IT, Moyer LA, Judson FN, Mottram K, et al: Incidence and risk factors for acute hepatitis B in the United States, 1982-1998: implications for vaccination programs. J Infect Dis. 2002, 185:713-9.

2. Raimondo G, Locarnini S, Pollicino T, Levrero M, Zoulim F, Lok AS, Taormina Workshop on Occult HBVIFM: Update of the statements on biology and clinical impact of occult hepatitis $B$ virus infection. J Hepatol 2019, 71(2):397-408.

3. Manzini P, Abate ML, Valpreda C, Milanesi P, Curti F, Rizzetto M, Smedile A: Evidence of acute primary occult hepatitis B virus infection in an Italian repeat blood donor. Transfusion 2009, 49(4):757-764.

4. Huang $X$, Hollinger FB: Occult hepatitis $B$ virus infection and hepatocellular carcinoma: a systematic review. J Viral Hepat 2014, 21(3):153-162.

5. Allain JP, Candotti D: Diagnostic algorithm for HBV safe transfusion. Blood Transfus 2009, 7(3):174-182.

6. Yip TC, Wong GL: Current Knowledge of Occult Hepatitis B Infection and Clinical Implications. Semin Liver Dis 2019, 39(2):249-260.

7. Candotti D, Lin CK, Belkhiri D, Sakuldamrongpanich T, Biswas S, Lin S, Teo D, Ayob Y, Allain JP: Occult hepatitis B infection in blood donors from South East Asia: molecular characterisation and potential mechanisms of occurrence. Gut 2012, 61(12):1744-1753.

8. Enjalbert F, Krysztof DE, Candotti D, Allain JP, Stramer SL: Comparison of seven hepatitis B virus (HBV) nucleic acid testing assays in selected samples with discrepant HBV marker results from United States blood donors. Transfusion 2014, 54(10):2485-2495.

9. Vermeulen M, Lelie N, Sykes W, Crookes R, Swanevelder J, Gaggia L, Le Roux M, Kuun E, Gulube S, Reddy R: Impact of individual-donation nucleic acid testing on risk of human immunodeficiency virus, hepatitis $B$ virus, and hepatitis $C$ virus transmission by blood transfusion in South Africa. Transfusion 2009, 49(6):1115-1125.

10. Liang X, Bi S, Yang W, Wang L, Cui G, Cui F, Zhang Y, Liu J, Gong X, Chen Y et al: Evaluation of the impact of hepatitis B vaccination among children born during 1992-2005 in China. J Infect Dis 2009, 200(1):39-47. 
11. Wang Z, Zeng J, Li T, Zheng X, Xu X, Ye X, Lu L, Zhu W, Yang B, Allain JP et al: Prevalence of hepatitis $B$ surface antigen (HBsAg) in a blood donor population born prior to and after implementation of universal HBV vaccination in Shenzhen, China. BMC Infect Dis 2016, 16:498.

12. Kang JW, Seo JH, Youn KW, Seo YI, Huh K, Choi GR, Min HK, Oh DJ, Jo HJ, Kim JN: Use of supplemental anti-HBc testing of donors showing non-discriminating reactive results in multiplex nucleic acid testing. Vox Sang 2017, 112(7):622-627.

13. Raimondo G, Allain JP, Brunetto MR, Buendia MA, Chen DS, Colombo M, Craxi A, Donato F, Ferrari C, Gaeta GB et al: Statements from the Taormina expert meeting on occult hepatitis B virus infection. J Hepatol 2008, 49(4):652-657.

14. Fopa D, Candotti D, Tagny CT, Doux C, Mbanya D, Murphy EL, Kenawy HI, El Chenawi F, Laperche S: Occult hepatitis B infection among blood donors from Yaounde, Cameroon. Blood Transfus 2019, 17(6):403-408.

15. Weusten $\mathrm{J}$, van Drimmelen $\mathrm{H}$, Vermeulen $\mathrm{M}$, Lelie $\mathrm{N}$ : A mathematical model for estimating residual transmission risk of occult hepatitis B virus infection with different blood safety scenarios. Transfusion 2017, 57(3pt2):841-849.

16. Chemin I, Trepo C: Clinical impact of occult HBV infections. Journal of clinical virology 2005, 34: Suppl 1: S15-21.

17. Gou H, Pan Y, Ge H, Zheng Y, Wu Y, Zeng J, Yang Z, Pan T, Cun W, Zhou G et al: Evaluation of an individual-donation nucleic acid amplification testing algorithm for detecting hepatitis $B$ virus infection in Chinese blood donors. Transfusion 2015, 55(9):2272-2281.

18. V Shyamala: Nucleic acid technology (NAT) testing for blood screening impact of individual donation and mini pool-NAT testing on analytical sensitivity, screening sensitivity and clinical sensitivity. ISBT Science Series 2014, 9: 315-324.

19. Charlewood R, Flanagan P: Ultrio and Ultrio Plus non-discriminating reactives: false reactives or not? Vox Sang 2013, 104(1):7-11.

20. Ye X, Li T, Shao W, Zeng J, Hong W, Lu L, Zhu W, Li C, Li T: Nearly half of Ultrio plus NAT nondiscriminated reactive blood donors were identified as occult HBV infection in South China. BMC Infect Dis 2019, 19(1):574.

21. Wang L, Chang L, Xie Y, Huang C, Xu L, Qian R, Zhu H, He Y, Li J, Huang H et al: What is the meaning of a nonresolved viral nucleic acid test-reactive minipool? Transfusion 2015, 55(2):395-404.

22. Lin CJ, Chen DS, Chen PJ: Epidemiology of HBV infection in Asian blood donors: emphasis on occult HBV infection and the role of NAT. J Clin Virol 2006, 36: Suppl: S33-44.

23. Chen CJ, Wang LY, Yu MW: Epidemiology of hepatitis B virus infection in the Asia-Pacific region. $J$ Gastroenterol Hepatol 2000, 15 Suppl:E3-6.

24. Ramachandran S, Groves JA, Xia GL, Saa P, Notari EP, Drobeniuc J, Poe A, Khudyakov N, Schillie SF, Murphy TV et al: Recent and occult hepatitis B virus infections among blood donors in the United States. Transfusion 2019, 59(2):601-611. 
25. Weusten J, Vermeulen M, van Drimmelen $\mathrm{H}$, Lelie $\mathrm{N}$ : Refinement of a viral transmission risk model for blood donations in seroconversion window phase screened by nucleic acid testing in different pool sizes and repeat test algorithms. Transfusion 2011, 51(1):203-215.

26. Deng X, Guo X, Li T, Laperche S, Zang L, Candotti D: Alternative hepatitis B virus DNA confirmatory algorithm identified occult hepatitis $B$ virus infection in Chinese blood donors with nondiscriminatory nucleic acid testing. Blood Transfus 2020.

27. Liang X, Bi S, Yang W, Wang L, Cui G, Cui F, Zhang Y, Liu J, Gong X, Chen Y et al: Epidemiological serosurvey of hepatitis $B$ in China-declining HBV prevalence due to hepatitis $B$ vaccination. Vaccine 2009, 27(47):6550-6557.

28. Cable R, Lelie N, Bird A: Reduction of the risk of transfusion-transmitted viral infection by nucleic acid amplification testing in the Western Cape of South Africa: a 5-year review. Vox Sang 2013, 104(2):93-99.

29. Hoshi Y, Hasegawa T, Yamagishi N, Mizokami M, Sugiyama M, Matsubayashi K, Uchida S, Nagai T, Satake M: Optimal titer of anti-HBs in blood components derived from donors with anti-HBc. Transfusion 2019, 59(8):2602-2611.

\section{Tables}

Table 1 Repeated discriminatory HBV testing of 190 NDR donations

HBV DNA-positive

$\begin{array}{llll}\begin{array}{l}\text { One time } \\ \text { positive }\end{array} & \begin{array}{l}\text { Two times } \\ \text { positive }\end{array} & \begin{array}{l}\text { Three times } \\ \text { positive }\end{array} & \text { Total } \\ & & \end{array}$

$34(55.7 \%)$

$18(29.5 \%)$

$9(14.8 \%)$

61
Negative for repeated dHBV

$129(67.9 \%)$

Table 2 The detection rate with the number of detection

Times to repeat Cumulative number of HBV DNA-positive Cumulative rate of HBV DNA-positive

\begin{tabular}{|c|c|c|}
\hline the first time & 18 & $29.5 \%$ \\
\hline the second time & 26 & $42.6 \%$ \\
\hline the third time & 40 & $65.6 \%$ \\
\hline the fourth time & 51 & $83.6 \%$ \\
\hline the fifth time & 61 & $100.0 \%$ \\
\hline
\end{tabular}


Table 3 Two HBV DNA-positive donations in MPX assay

\begin{tabular}{lll} 
Sample ID & MP-format]Ctn & $\begin{array}{l}\text { ID-format } \\
\text { [Ct }\end{array}$ \\
\hline 33 & 39.3 & 38.3 \\
\hline 60 & 47.2 & 38.1
\end{tabular}

Table 4 Serological distributions of 190 NRD donations and 100 dHBV-initially-reactive donations

\begin{tabular}{|lllllll} 
Serological makers & \multicolumn{2}{l}{ dHBV-initially-nonreactive (NDR) } & \multicolumn{3}{l}{ dHBV-initially } \\
\cline { 2 - 4 } & HBV DNA-positive & Unclassified & Total & -reactive & Table 5 \\
\cline { 2 - 3 } Anti-HBc+/anti-HBs+ & 28 & 67 & 95 & 33 & $\begin{array}{l}\text { Serological } \\
\text { distributions and } \\
\text { population }\end{array}$ \\
\hline Anti-HBc+/anti-HBs- & 33 & 34 & 67 & 57 & characteristics of \\
\hline Anti-HBc-/anti-HBs+ & 2 & 14 & 16 & 2 & all confirmed OBI \\
\hline Anti-HBc-/anti-HBs- & 0 & 12 & 12 & 8 & donors \\
\hline Total & 63 & 127 & 190 & 100 &
\end{tabular}

\begin{tabular}{lllll} 
Maker & & $\begin{array}{l}\text { dHBV initially nonreactive } \\
\text { (NDR) }\end{array}$ & dHBV initially reactive & Total \\
\hline \multirow{2}{*}{$\begin{array}{l}\text { Serological } \\
\text { distribution }\end{array}$} & Anti-HBc+/anti-HBs+ & 28 & 33 & 61 \\
\cline { 2 - 5 } & Anti-HBc+/anti-HBs- & 33 & 57 & 90 \\
\cline { 2 - 5 } Gentle & Anti-HBc-/anti-HBs+ & 2 & 2 & 4 \\
\hline Status & Male & 43 & 60 & 103 \\
\cline { 2 - 5 } & Female & 20 & 32 & 52 \\
\hline Age & Repeat-time & 40 & 46 & 69 \\
(years) & Range & $20-55$ & 46 & 86 \\
\cline { 2 - 5 } & Median & 45 & $20-55$ & $20-55$ \\
\hline
\end{tabular}




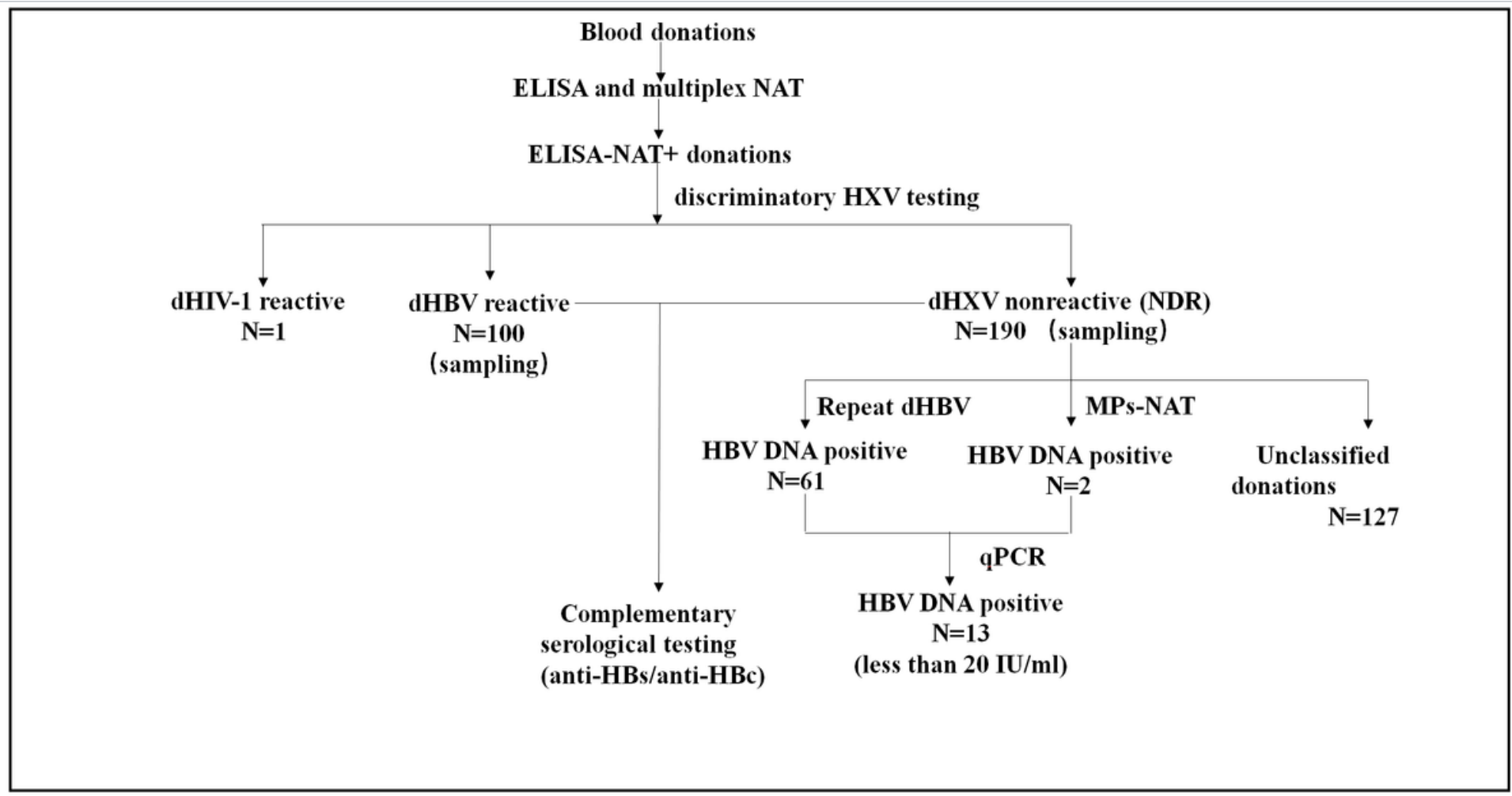

Figure 1

Ultrio Plus NAT screening and confirmatory testing flow

\section{Supplementary Files}

This is a list of supplementary files associated with this preprint. Click to download.

- Supplementarymaterials.docx 